\title{
Standardisasi ${ }^{129}$ I menggunakan sistem koinsidensi $\gamma(\mathrm{NaI})-\gamma(\mathrm{NaI})$
}

\author{
Pujadi, Gatot Wurdiyanto \\ Pusat Teknologi Keselamatan dan Metrologi Radiasi BATAN \\ Jalan Lebak Bulus Raya No. 49 Jakarta Selatan \\ pujadi@batan.go.id
}

\begin{abstract}
Abstrak - Telah dilakukan penelitian standardisasi secara absolut radionuklida ${ }^{129}$ I menggunakan sistem koinsidensi $\gamma(\mathrm{NaI})-$ $\gamma(\mathrm{NaI})$ dengan metode perunut. Radionuklida ${ }^{129} \mathrm{I}$ memancarkan radiasi foton yang tidak serempak atau peluruhan bukan cascade, sehingga pengukuran aktivitas menggunakan metode koinsidensi memerlukan radionuklida lain sebagai perunut. ${ }^{125}$ I digunakan sebagai perunut karena peluruhannya serempak dan mempunyai kesamaan sifat kimia serta kesesuaian daerah energi foton yaitu pada $27-40 \mathrm{keV}$. Sumber ${ }^{125} \mathrm{I}$ dan ${ }^{129} \mathrm{I}$ dalam bentuk cairan Kalium Iodida (KI) dalam $\mathrm{H}_{2} 0$, masingmasing dipreparasi sendiri-sendiri menjadi cuplikan sumber bentuk titik padat dalam bentuk AgI dengan menambahkan $\mathrm{AgNO}_{3}$. Berat cuplikan ditentukan secara gravimetri, berat masing-masing berkisar antara 10 - $30 \mathrm{mg}$ setiap cuplikan. Tahap pertama dilakukan penentuan aktivitas perunut, menggunakan sistem koinsidensi $\gamma(\mathrm{NaI})-\gamma(\mathrm{NaI})$. Pengukuran dilakukan pada daerah puncak energi gamma tunggal $13-42 \mathrm{keV}$ (single peak). Tahap kedua dilakukan pengukuran sumber campuran ${ }^{129} \mathrm{I}$ dan ${ }^{125} \mathrm{I}$ (sandwiched), menggunakan peralatan dan seting yang sama dengan kondisi pengukuran aktivitas perunut. Hasil pengukuran aktivitas ${ }^{129} \mathrm{I}$ menggunakan perunut ${ }^{125} \mathrm{I}$, diperoleh aktivitas sebesar 998,56 $\pm 1,01 \% \mathrm{~Bq} / \mathrm{gr}$ dengan waktu acuan 1 agustus 2012. Nilai aktivitas ${ }^{129} \mathrm{I}$ tersebut bersesuaian dengan hasil pengukuran aktivitas $\mathrm{PTB}-$ Jerman menggunakan kamar pengionan-4 $\pi \gamma$, dengan perbedaan $\quad 0,14 \%$.
\end{abstract}

Kata kunci: standardisasi, sistem koinsidensi $\gamma(\mathrm{NaI})-\gamma(\mathrm{NaI})$, aktivitas, ${ }^{129} I \quad$, perunut $\quad{ }^{125} \mathrm{I}$

Abstract - The research of absolute standardization of ${ }^{129} \mathrm{I}$ have been carried out by $\gamma(\mathrm{NaI})-\gamma(\mathrm{NaI})$ coincidence system with tracer method. Photon radiation emitting of ${ }^{129} \mathrm{I}$ is not simultaneous, so that absolute activity measurement using this method require radionuclide tracer. $\quad{ }^{125} \mathrm{I}$ can be used as a tracer, because emits two or more photons radiation simultaneously and it has similarities in the chemical properties with ${ }^{129} \mathrm{I}$ and both radionuclides emitting photons with similar energies from about $27-40 \mathrm{keV}$. The sources of ${ }^{125} \mathrm{I}$ and ${ }^{129} \mathrm{I}$ in the form of liquid of potassium iodide (KI) in $\mathrm{H}_{2} 0$ solution was prepared individual into solid point source in the form of $\mathrm{AgI}$ by adding $\mathrm{AgNO}_{3}$. The weight of sample sources were determined by gravimetric, between $10-30 \mathrm{mg}$ of each sample. In the first step the activity concentration of tracer is measured by a $\gamma(\mathrm{NaI})-\gamma(\mathrm{NaI})$ coincidence system. Measurement were taken at the gamma energy region of single peak from 13 to $42 \mathrm{keV}$. The second step photons are counted from mixed samples (sandwiched) of ${ }^{129} \mathrm{I}$ and of the ${ }^{125} \mathrm{I}$ with the known activity concentration, using the same measuring equipment and setting is used as for the activity measurement of a tracer. The measurement result of avtivity ${ }^{129} \mathrm{I}$ using ${ }^{125} \mathrm{I}$ tracer was obtained 998,56 $\pm 1,01 \% \mathrm{~Bq} / \mathrm{gr}$ at reference time August 1 , 2012 The activity value agrees with the results of PTB-Jerman measurements using the calibrated $4 \pi \gamma$ ionization chamber with difference $0.14 \%$.

Key words: standardization, $\gamma(\mathrm{NaI})-\gamma(\mathrm{NaI})$ coincidence system, activity, ${ }^{129} \mathrm{I}$, tracer $\quad{ }^{125} \mathrm{I}$.

\section{PENDAHULUAN}

Pada kegiatan pengukuran radiasi diperlukan sumber standar radionuklida sebagai acuan dalam pengukuran atau untuk kalibrasi alat ukur radiasi. Salah satu faktor yang mempengaruhi ketelitian dan keakuratan pengukuran radioaktivitas adalah sumber standar radionuklida yang digunakan sebagai acuan. Sumber standar radionuklida yang digunakan oleh pemangku kepentingan di Indonesia, seperti lembaga penelitian, industri dan rumah sakit sebagian besar masih impor dari negara lain diantaranya dari USA, Jerman, Perancis dll.

Untuk mengurangi mengurangi ketergantungan produk luar negeri, maka penelitian dan pengembangan dibidang metrologi radiasi khusunya standardisasi radionuklida sangat perlu dilakukan agar dapat memproduksi sumber standar radionuklida sendiri
Untuk keperluan pembuatan sumber standar radionuklida perlu dikembangkan metode pengukuran secara absolut atau metode langsung ( direct methods). Ketepatan pengukuran menggunakan metode absolut biasanya lebih baik dibandingkan dengan metode relatif, karena pengukuran dengan metode relatif sangat bergantung pada sumber standar yang digunakan. Selama ini pengukuran aktivitas radionuklida ${ }^{129} \mathrm{I}$ hanya dilakukan dengan metode relative. Pada makalah ini dibahas standardisasi radionuklida ${ }^{129} \mathrm{I}$ secara absolut menggunakan sistem koinsidensi $\gamma(\mathrm{NaI})-\gamma(\mathrm{NaI})$ dengan metode perunut.

\section{TEORI}

A. Yodium-129

Radionuklida ${ }^{129} \mathrm{I}$ adalah merupakan produk dari proses fisi, yang bersifat volatile dengan waktu paro yang 
cukup panjang $\left(1,57 \times 10^{7}\right)$ tahun $[2,3,4] . \quad{ }^{129} \mathrm{I}$ meluruh melalui pancaran zarah $\beta$, dengan $\mathrm{E}_{\beta}$ max. $151 \mathrm{keV}$, kemudian menuju ke ground state $39,6 \mathrm{keV}$ dari ${ }^{129} \mathrm{Xe}$ dengan memancarkan foton pada energi 29,5 - 39,6 keV. Transisi kekeadaan dasar memencarkan sinar $-\gamma$ sebesar $7,42 \%$ bagian terbesar terdiri dari $K$ x-rays dengan energi antara 29,5 - 34,5 keV [1,2,3]. Sumber standar radionuklida ${ }^{129} \mathrm{I}$ banyak digunakan untuk kalibrasi detektor pada energi rendah, selain itu digunakan pula pada kegiatan pengawasan /pengelolaan bahan bakar nuklir (IAEA 1987) [1].

Radionuklida ${ }^{129}$ I memacarkan foton lebih dari satu, tetapi pancaran fotonnya tidak, pengukuran aktivitas menggunakan sistem koinsidensi $\gamma(\mathrm{NaI})-\gamma(\mathrm{NaI})$ tidak dapat dilakukan langsung karena tidak akan diperoleh laju cacah koinsiden, pada pengukuran ini memerlukan perunut. $[1,2]$. Radionuklida yang digunakan sebagai perunut harus yang memancarkan dua atau lebih radiasi foton serempak, kesamaan komposisi kimia dan daerah energi pancaran foton. Radionuklida yang cocok untuk perunut pada pengukuran aktivitas ${ }^{129} \mathrm{I}$ adalah $\quad{ }^{125} \mathrm{I} \quad[1,2]$.

Peluruhan radionuklida ${ }^{125} \mathrm{I}$ mirip dengan ${ }^{129} \mathrm{I}$, keduanya hanya mempunyai satu keadaan tereksitasi ,exited state, ${ }^{129} \mathrm{I}$ pada $39,6 \mathrm{keV}\left({ }^{129} \mathrm{Xe}\right)$ dan ${ }^{125} \mathrm{I}$ pada 35,5 $\mathrm{keV}\left({ }^{125} \mathrm{Te}\right)$. Transisi ke keadaan dasar ${ }^{129} \mathrm{I}$ memancarkan sinar- $\gamma \quad 7,42 \%$ dan I-125 memancarkan $6,67 \%$, pancaran $K x$-rays ${ }^{129} \mathrm{I}$ dengan energi $29,5-34,5 \mathrm{keV}\left({ }^{129} \mathrm{Xe}\right)$ dan untuk ${ }^{125} \mathrm{I}$ dengan energi $27,2-31,8 \mathrm{keV}\left({ }^{125} \mathrm{Te}\right) \quad[1,2,3]$.

Standardisasi ${ }^{129} \mathrm{I}$ menggunakan sistem koinsidensi $\gamma(\mathrm{NaI})-\gamma(\mathrm{NaI})$ dengan perunut ${ }^{125} \mathrm{I}$ dilakukan dua tahap. Tahap pertama pengukuran aktivitas ${ }^{125} \mathrm{I}$, tahap kedua pengukuran aktivitas ${ }^{129} \mathrm{I}$ dan ${ }^{125} \mathrm{I}$ yang sudah diketahui aktivitasnya, peralatan dan seting sama dengan peralatan yang digunakan untuk pengukuran aktivitas ${ }^{125} \mathrm{I}[1,2]$.

\section{B. $\quad$ Sistem koinsidensi $\gamma(\mathrm{NaI})-\gamma(\mathrm{NaI})$}

Sistem koinsidensi $\gamma(\mathrm{NaI})-\gamma(\mathrm{NaI})$ merupakan sistem peralatan untuk pengukuran aktivitas secara absolut menggunakan dua buah detektor $\mathrm{NaI}(\mathrm{Tl})$ yang diletakkan berhadap-hadapan dan dihubungkan dengan unit koinsidensi [1,3-7]. Kedua buah detektor yang digunakan sebaiknya memiliki ukuran yang hampir sama, efisiensi intrinsik yang serupa untuk semua jenis foton, sehingga memungkinkan terjadinya cacah koinsidensi [1]. Cuplikan yang diukur berupa sumber titik, yang diletakkan diantara kedua buah detektor tersebut $[1,3]$. Ada dua metode pengukuran aktivitas menggunakan sistem ini yaitu dengan posisi atau jarak sumber ke detektor tetap (J.G.V.Taylor), dan metode variasi jarak posisi sumber terhadap detektor ( H.Schrader dan KF walz) [4,6].

\section{Pengukuran aktivitas ${ }^{125} I$}

Metode pengukuran aktivitas secara absolut ${ }^{125} \mathrm{I}$ menggunakan sistem koinsidensi foton-foton, dilakukan dengan dua metode yaitu jarak sumber ke detektor tetap dan variasi jarak sumber ke detektor untuk mendapatkan variasi efisiensi dari masing-masing detektor $[3,4,5]$. Gerbang saluran gamma ditentukan pada daerah energi foton gamma yang diinginkan $[3,4,5]$.

Tabel 1. Energi, probabilitas emisi dan fluorescence

\begin{tabular}{lcccc}
\multicolumn{4}{c}{ escape radionuklida ${ }^{125} \mathrm{I}$ dan } & ${ }^{129} \mathrm{I}[2]$. \\
\hline Radionuklida Radiasi & $\mathrm{E}_{\gamma}(\mathrm{keV})$ & $p_{\gamma}$ & $f_{\gamma}$ \\
\hline${ }^{125} \mathrm{I}$ & TeK(e.c.) & 28,07 & 0,699 & 0,0 \\
${ }^{125} \mathrm{I}$ & $\mathrm{TeK}($ e.c. $)$ & 28,07 & 0,696 & 0,0 \\
${ }^{129} \mathrm{I}$ & $\mathrm{Xe} \mathrm{K}$ & 29,46 & 0,200
\end{tabular}

\begin{tabular}{lllll}
${ }^{129} \mathrm{I}$ & 0,0 & & & \\
${ }^{129} \mathrm{I}$ & & $\mathrm{Xe} \mathrm{Kal}$ & 29,78 & $0,3710,0$ \\
${ }^{129} \mathrm{I}$ & & $\mathrm{Xe} \mathrm{K} \beta 2$ & 33,60 & $0,1090,254$ \\
${ }^{125} \mathrm{I}$ & & $\mathrm{Xe} \mathrm{K} \beta 2$ & 34,50 & $0,0240,249$ \\
${ }^{129} \mathrm{I}$ & 0,245 & Sinar- $\gamma$ & 35,49 & 0,0667 \\
& & & & \\
& 0,222 & & 39,58 & 0,0746 \\
\hline
\end{tabular}

Untuk menghitung aktivitas ${ }^{125} \mathrm{I}$ dengan metode ekstrapolasi efisiensi menggunakan persamaan yang dijabarkan oleh H Schrader dan KF Walz [4] dan untuk jarak tetap menggunakan persamaan JGV Taylor [6].

\section{Pengukuran aktivitas ${ }^{129} I$}

Untuk menentukan aktivitas sumber ${ }^{129} \mathrm{I}$ menggunakan sistem koinsidensi $\gamma(\mathrm{NaI})-\gamma(\mathrm{NaI})$, pencacahan sumber ${ }^{129}$ I dilakukan bersama-sama dengan sumber perunut ${ }^{125} \mathrm{I}$ [2]. Metode pengukuran dan seting alat harus sama dengan yang digunakan pada penentuan aktivitas perunut ${ }^{125} \mathrm{I}$ [2]. Untuk menghitung aktivitas ${ }^{129} \mathrm{I}$ pada sampel campuran tersebut digunakan persamaan sebagai berikut $[2,3]$ :

$$
A_{(129)}=\frac{1}{k_{(129)}}\left(2 \sqrt{\frac{y}{(1-x)}} k_{(125)} A_{(125)}-\left(1+k_{(125)}\right) A_{(125)}\right)
$$

(1)

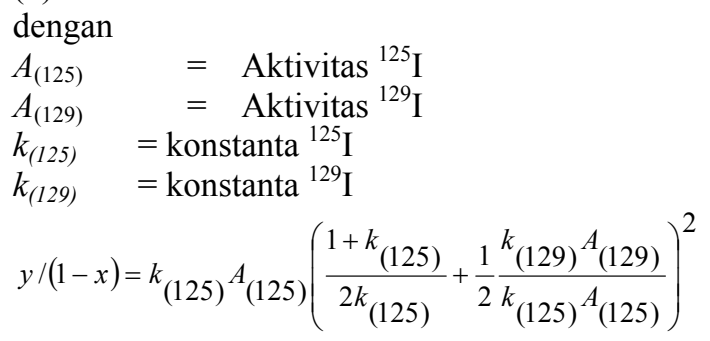

(2)

Nilai parameter $f_{\gamma(5)}$ dan $f_{\gamma(9)}$ diperoleh dari Tabel 1 (Coursol 1982, 1984 dikutip oleh H Schrader ） [2,11] :

$k_{(125)}=\frac{P_{e K(5)} \omega_{k}+p_{\gamma(5)}\left(1-f_{\gamma(5)}\right)}{P_{K} \omega_{k}}$

$$
k_{(129)}=\frac{P_{e k(9)}{ }^{\omega} K(9) \sum_{j}^{4} r_{j}\left(1-f_{j}\right)+p_{\gamma(9)}\left(1-f_{\gamma(9)}\right)}{P_{K}{ }^{\omega} k}
$$


Data dari peluruhan I-125 [2]:

$P_{e K(5)}=$ Probabilitas pancaran elektron kulit K $(0,793)$

$\omega_{k} \quad=$ Yield fluoresensi kulit-K $(0,875 \pm 0,004)$

$p_{\gamma(5)}=$ Probabilitas pancaran foton $-\gamma \quad 35,49 \mathrm{keV}(0,0667)$

$P_{K} \quad=$ Probabilitas tangkapan elektron kulit-K $\quad(0,8007)$

$f_{\gamma(5)}=$ Probabilitas fluo.escape foton $-\gamma \quad 35,49 \mathrm{keV}$

$(0,245)$

Data dari peluruhan I-129 [2] :

$P_{e K(9)}=$ Probabilitas pancaran elektron kulit-K $(0,789)$

$\omega_{k(9)}=$ Yield fluoresensi kulit-K $(0,888)$

$p_{\gamma(9)}=$ Probabilitas pancaran foton- $\gamma \quad 39,58 \mathrm{keV}(0,0746)$

$f_{\gamma(9)}=$ Probabilitas fluo. escape foton $-\gamma 35,58 \mathrm{keV}(0,222)$

Nilai $\mathrm{x}$ dihitung dengan persamaan :

$$
x=\left(\frac{a_{1}+a_{2}}{2}-\frac{a_{1} a_{2}}{4}\right)
$$

(5)

$$
\begin{aligned}
& \frac{N_{c}}{N_{2}}\left(1-\frac{1}{2} \frac{N_{c}}{N_{1}}\right) \div\left(1-\frac{1}{4} \frac{N_{c}^{2}}{N_{1} N_{2}}\right)=a_{1} \\
& \frac{N_{c}}{N_{1}}\left(1-\frac{1}{2} \frac{N_{c}}{N_{2}}\right) \div\left(1-\frac{1}{4} \frac{N_{c}^{2}}{N_{1} N_{2}}\right)=a_{2}
\end{aligned}
$$

$$
\begin{array}{ll}
N_{1} & =\text { Laju cacah detektor-1 terkoreksi } \\
N_{2} & =\text { Laju cacah detektor-2 terkoreksi } \\
N_{\mathrm{c}} & =\text { Laju koinsidensi terkoreksi }
\end{array}
$$

\section{EKSPERIMEN}

\section{A. Bahan dan Peralatan}

Pada penelitian ini digunakan perunut zat radioaktif ${ }^{125} \mathrm{I}$, diperoleh dari P2RR - Serpong dalam bentuk larutan, komposisi kimia $\left(\mathrm{Na}_{2} \mathrm{SO}_{3}+\mathrm{LiOH}+\mathrm{KI}\right)$ dalam $\mathrm{H}_{2} \mathrm{O}$. Zat radioaktif ${ }^{129} \mathrm{I}$ dalam bentuk larutan, komposisi kimia (NaI $60 \mathrm{mg} / \mathrm{L}+\mathrm{Na}_{2} \mathrm{~S}_{2} \mathrm{O}_{3} 45 \mathrm{mg} / \mathrm{L}+\mathrm{HCHO} 1,2 \mathrm{~g} / \mathrm{L}$ ) diperoleh dari PTB - Jerman. Untuk proses pengenceran menggunakan larutan pengemban yang dibuat dari campuran : $50 \mu \mathrm{g} / \mathrm{L}$ $\mathrm{Na}_{2} \mathrm{SO}_{3}+50 \mu \mathrm{g} / \mathrm{L} \mathrm{Li}(\mathrm{OH})+50 \mu \mathrm{g} / \mathrm{L} \mathrm{KI}$ dalam $\mathrm{H}_{2} \mathrm{O}[1,3]$. Larutan $\mathrm{Ag}(\mathrm{NO})_{3} \quad 0,1 \mathrm{~N}$ digunakan untuk mengikat iodium menjadi endapan AgI. Larutan Catanac $\left(\mathrm{SiO}_{2}\right)$ digunakan sebagai katalis untuk memperhalus terbentuknya kristal [5 ]. Penyangga sumber dipergunakan plastik polietilen (PE) dengan ketebalan $\pm 25 \mu \mathrm{g} / \mathrm{cm}^{3}$. Sedangkan cuplikan dalam bentuk cair dibuat dalam wadah ampul gelas standar PTKMR volume $5 \mathrm{ml}$.

Alat ukur aktivitas menggunakan dua buah detektor $\mathrm{NaI}(\mathrm{Tl})$. Kristal detektor $\mathrm{NaI}(\mathrm{Tl})$ dengan ketebalan $6 \mathrm{~mm}$ dan diameter $75 \mathrm{~mm}$ (3 inchi). Sistem pencacah ini dilengkapi dengan modul-modul penguat ( amplifier ), SCA (single channel analyzer), gate and delay, koinsiden unit, sumber pulsa (pulse generator), pencatat pulsa ( counter), MCA ( muti channel analyzer) dan osiloskop.

\section{B. Pembuatan cuplikan}

Cuplikan untuk pengukuran menggunakan sistem koinsidensi $\gamma(\mathrm{NaI})-\gamma(\mathrm{NaI})$ dan spektrometer gamma dalam bentuk titik padatan, sedangkan untuk pengukuran menggunakan kamar pengionan $4 \pi \gamma$ dalam bentuk cair pada wadah ampul gelas dengan berat $(2 \pm 0,5 \%)$ gram. Pembuatan cuplikan radionuklida ${ }^{129} \mathrm{I}$ dan ${ }^{125} \mathrm{I}$ ( sebagai perunut) pada prinsipnya sama. Masing-masing larutan ${ }^{125}$ I dan larutan ${ }^{129}$ I di preparasi menjadi sumber bentuk titik padataan dengan jalan diteteskan, diatas penyangga plastik tipis (PE), yang sebelumnya telah ditetesi terlebih dahulu dengan $\mathrm{AgNO}_{3}$ dan Catanac. Berat masing-masing cuplikan ditentukan dengan timbangan semi-mikro. Disiapkan cuplikan ${ }^{129} \mathrm{I}$ dan ${ }^{125} \mathrm{I}$ masing-masing 5 buah dengan berat bervariasi dari 6,73 - 51,74 mili gram. Setelah kering cuplikan ditutup dengan plastik tipis (PE) untuk mencegah terjadinya kontaminasi. Pembuatan cuplikan dalam bentuk cair dengan wadah ampul gelas PTKMR, masing-masing 2 buah cuplikan, dengan berat berkisar 1,98 sampai 2,12 gram setiap ampulnya, kemudian ampul ditutup rapat .

\section{Pencacahan cuplikan ${ }^{125} I$ dan campuran ( ${ }^{125} I$ dan}

Pertama-tama dilakukan pencacahan terhadap cuplikan ${ }^{125} \mathrm{I}$, cuplikan diletakkan di tengah-tengah diantara kedua buah detektor $\mathrm{NaI}(\mathrm{Tl})$, keluaran dari penguat (amplifier) dihubungkan dengan penganalisa salur ganda ( Multi Channel Analyzer = MCA ). Kemudian dengan bantuan sumber pulsa (pulse generator), ditentukan gerbang /daerah energi gamma pada daerah single peak energi 13 $42 \mathrm{keV}$. . Pencacahan selanjutnya dilakukan terhadap cuplikan campuran $\left({ }^{125} \mathrm{I}\right.$ dan $\left.{ }^{129} \mathrm{I}\right)$ dengan seting dan posisi sumber yang sama, dengan pada waktu pencacahan cuplikan ${ }^{125} \mathrm{I}$.

\section{HASIL DAN PEMBAHASAN}

Pada Tabel 2, disajikan hasil pengukuran aktivitas ${ }^{125}$ I, yang digunakan sebagai perunut. Gerbang saluran gamma dibatasi pada single peak yaitu pada daerah energi $13-42 \mathrm{keV}$. Dengan pemasangan diskriminator bawah 13 $\mathrm{keV}$ diharapkan laju cacah sinar-x dari kulit L energi $\quad(3,3$ $-4,8) \mathrm{keV}\left({ }^{125} \mathrm{Te}\right)$ tidak ikut tercacah $[2,3]$. Laju cacah dikoreksi terhadap cacah latar, waktu mati detektor, laju cacah koinsiden dikoreksi terhadap cacah latar, waktu mati detektor dan waktu resolusi. Hasil pengukuran aktivitas ${ }^{125}$ I terhadap lima buah cuplikan, dengan variasi berat diperoleh nilai aktivitas per satuan berat $(\mathrm{mg})$ relatif sama dengan penyimpangan $0,47 \%$. Ketidakpastian pengukuran masing-masing cuplikan (statistik pencacahan) berkisar antara 0,43 - 48\%. Ketidakpastian gabungan ( combined relative standard uncertainty or quadratic sum) ditentukan dengan parameter ketidakpastian pengukuran tipe A dan tipe B, disajikan pada Tabel 3. Nilai aktivitas ${ }^{125} \mathrm{I}$ yang diperoleh adalah 431,12 $\pm 0,70 \% \quad \mathrm{~Bq} / \mathrm{mg}$, waktu acuan 01 Agustus 2012, jam: 00.00. WIB, nilai ketidakpastian adalah ketidakpastian gabungan

Untuk menentukan nilai aktivitas ${ }^{129} \mathrm{I}$, pengukuran dilakukan terhadap sumber campuran ${ }^{129} \mathrm{I}$ dan ${ }^{125} \mathrm{I}$ dimana aktivitas ${ }^{125} \mathrm{I}$ sudah diketahui. Kedua sumber ditumpuk menjadi satu (sandwich), kemudian diukur, menggunakan 
sistem koinsidensi $\gamma(\mathrm{NaI})-\gamma(\mathrm{NaI})$ dengan seting dan kondisi sama dengan pada waktu mencacah ${ }^{125} \mathrm{I}$.

Hasil cacah $\mathrm{N}_{1}$ dan $\mathrm{N}_{2}$, dari sumber campuran $\left({ }^{129} \mathrm{I}+{ }^{125} \mathrm{I}\right)$ yang diperoleh lebih tinggi dari hasil cacah $\mathrm{N}_{1}$ dan $\mathrm{N}_{2}$ sumber tunggal ${ }^{125}$ I pada posisi yang sama, karena cacah $\mathrm{N}_{1}$ dan $\mathrm{N}_{2}$ merupakan gabungan dari kedua radionuklida, tetapi $\mathrm{N}_{\mathrm{c}}$ yang diperoleh relatif sama bahkan lebih kecil, hal ini karena laju cacah koinsiden hanya berasal dari peluruhan ${ }^{125} \mathrm{I}$. Dengan variasi jarak sumberdetektor 5-120 mm diperoleh nilai paramater $-\mathrm{x}$ berkisar antara $0,098-0,041$, nilai ini sangat tergantung pada $\mathrm{N}_{\mathrm{c}} /$ $\mathrm{N}_{1,2}$ [2].

Untuk menghitung nilai aktivitas ${ }^{129} \mathrm{I}, \mathrm{A}_{(129)}$ dengan persamaan (1) maka nilai $\mathrm{k}_{(125)}$ dan $\mathrm{k}_{(129)}$ harus dihitung terlebih dahulu menggunakan persamaan (3) dan (4).

Tabel 2. Hasil pengukuran aktivitas I-125

\begin{tabular}{|c|c|c|}
\hline No. cuplikan & Berat & $\mathrm{No} / \mathrm{mg}(\mathrm{Bq} / \mathrm{mg}$ \\
\hline 01 & 12,04 & $430,61 \pm 0,46$ \\
\hline 02 & 11,97 & $431,72 \pm 0,43$ \\
\hline 03 & 12,16 & $431,16 \pm 0,48$ \\
\hline 04 & 6,73 & $431,21 \quad \pm 0,44$ \\
\hline \multirow[t]{2}{*}{05} & 12,44 & $430,92 \pm 0,45$ \\
\hline & Rata-rata & $431,12 \pm 0,45$ \\
\hline
\end{tabular}

Tabel 3. Ketidakpastian gabungan pengukuran ${ }^{125} \mathrm{I}$ dan ${ }^{129} \mathrm{I}$.

\begin{tabular}{|c|c|c|}
\hline \multirow{2}{*}{ 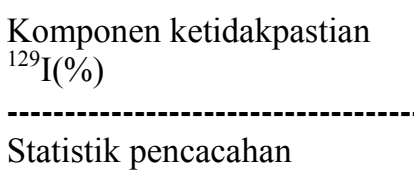 } & \multicolumn{2}{|c|}{${ }^{125} \mathrm{I}(\%)$} \\
\hline & 0,47 & 1,01 \\
\hline Waktu cacah & 0,035 & 0,035 \\
\hline Penimbangan & 0,05 & 0,05 \\
\hline Waktu mati & 0,005 & 0,005 \\
\hline Cacah latar & 0,50 & 0,50 \\
\hline Waktu resolusi & 0,05 & 0,05 \\
\hline Waktu paro & 0,10 & 0,10 \\
\hline Radionuklida pengotor & 0,00 & 0,00 \\
\hline Ekstrapolasi (variasi jarak) & 0,00 & 0,50 \\
\hline Ketidak pastian gabungan: & 0,70 & 1,24 \\
\hline
\end{tabular}

Data energi, probabilitas emisi dan f $\gamma$ dari data Tabel 1.

Pada persamaan (3) untuk menentukan nilai $\mathrm{k}_{(125)}$, probabilitas fluorescene escape (f $\gamma$ ) untuk ${ }^{125} \mathrm{I}$ pada energigamma $35,49 \mathrm{keV} \quad f \gamma=0,245$. Nilai $\mathrm{k}_{(125)}$ yang diperoleh sebesar 1,062, nilai ini berbeda sebesar 0,005 dengan nilai yang didapat oleh H SCHRADER (1990)yaitu sebesar 1,067. Perbedaan ini dikarenakan pemakaian parameter yang digunakan berbeda, dengan perkembangan nilai data nuklir yang ada, tetapi pengaruhnya sangat kecil pada hasil akhir. Untuk menentukan nilai $\mathrm{k}_{(129)}$ menggunakan persamaan (4), probabilitas pancaran sinar-x kulit-K pada peluruhan ${ }^{129} \mathrm{I}$ yaitu fraksi $\quad P_{e k(9)} \omega_{K(9)} \sum_{j}^{4} r_{j}\left(1-f_{j}\right)$ dihitung untuk : $\mathrm{K}_{\alpha 2}$ $(29,46 \mathrm{keV}) ; \mathrm{K}_{\alpha 1}(29,78 \mathrm{keV}) ; \mathrm{K}_{\beta 1}(33,6 \mathrm{keV}) ; \mathrm{K}_{\beta 2}(34,5$ $\mathrm{keV})$ dengan $\mathrm{p}_{\gamma}=P_{e k(9)} \omega_{K(9)}{ }^{r} j ; \quad(j=1,4)$ dan $\sum_{j}^{4} r_{j}=1$. Nilai $\mathrm{k}_{(129)}$ diperoleh sebesar 1,038, nilai $\mathrm{k}_{(129)}$ yang diperoleh H.SCHRADER (1990) adalah 1,039, dengan perbedaan 0,001 relatif cukup kecil pengaruhnya terhadap hasil akhir $\mathrm{A}_{(129)}$. Pada Tabel 4 disajikan hasil pengukuran aktivitas ${ }^{129} \mathrm{I}$ menggunakan sistem koinsidensi $\gamma(\mathrm{NaI})-\gamma(\mathrm{NaI})$ dengan perunut ${ }^{125} \mathrm{I}$. Terlihat pada cuplikan no.3 nilai hasil pengukuran yang diperoleh mempunyai perbedaan yang paling besar sekitar $1,15 \%$ terhadap rerata, hal ini kemungkinan karena massa Tabel 4. Hasil pengukuran aktivitas ${ }^{129} \mathrm{I}$

\begin{tabular}{|c|c|c|c|}
\hline No Cuplikan & Berat (mg) & Aktivitas & $(\mathrm{Bq} / \mathrm{mg})$ \\
\hline 01 & 40,37 & 994,49 & $\pm 1,05 \%$ \\
\hline 02 & 51,36 & 992,73 & $\pm 1,26 \%$ \\
\hline 03 & 13,41 & $1010,22 \pm$ & $\neq 1,80 \%$ \\
\hline 04 & 44,78 & 998,01 & $\pm 0,98 \%$ \\
\hline \multirow[t]{2}{*}{05} & 29,13 & 997,31 & $\pm 1,01 \%$ \\
\hline & Rata-rata & 998,56 & $\pm 1,01 \%$ \\
\hline
\end{tabular}

terlalu kecil sehingga memerlukan waktu pencacahan yang lebih panjang. Hasil rerata dari lima buah cuplikan adalah 998,56 \pm 1,24\% Bq/gram, dengan ketidakpastian adalah ketidakpastian gabungan Tabel 3. Perbedaan hasil pengukuran yang dilakukan PTB-Jerman menggunakan kamar ionisasi yang terkalibrasi dengan standar primer adalah $0,14 \%$.

\section{KESIMPULAN}

Pengukuran aktivitas secara absolut radionuklida ${ }^{129} \mathrm{I}$ menggunakan menggunakan sistem koinsidensi $\gamma(\mathrm{NaI})-$ $\gamma(\mathrm{NaI})$ dengan metode perunut ${ }^{125} \mathrm{I}$ telah dapat dilakukan dengan baik di PTKMR - BATAN dan hasilnya cukup akurat.

\section{UCAPAN TERIMA KASIH}

Kepada saudara Holnisar diucapkan terima kasih atas bantuannya pada waktu seting alat.

\section{PUSTAKA}

[1] H.Schrader .Standardization of ${ }^{129} I$ by tracer Method with Photon-photon Coincidences from the Decay of ${ }^{125}$ I. Appl.Radiat.Isot.41, No.4, pp.417421, 1990. 
[2] TdeR, (2004). Table de Radionuclides. Atomic and

Nuclear Data, Recommended data/table. BNMLNHB/CEA - Table de Radionuclides -

CEA.

[3] G Ratel, J.W. Muller, Trial comparison of activity measurement of solution of I-125. BIPM Report -88/2, February 1988.

[4] H Schrader and KF Walz (1987) Standardization of ${ }^{125} I$ byphoton-photon coincidence counting and efficiency extrapolation. Appl.Radiat.Isot.41,417.

[5] H.Schrader. (2006) Photon - photon coincidences for activity determination $\quad:^{.125} I$ and other radionuclides. Appl.Radiat.Isot. 64 11791185.

[6] J.G.V. Taylor, Standardization of Radionuclides, IAEA Vienna, 1967, p.341.

[7] Maria Sahagia, C.Ivan.E.L.Grigorescu, Anamaria Razdolescu (2008), Standardization of ${ }^{125}$ I by the coincidence method and practical applications. Appl.Radiat.Isot.66 . 895-899 